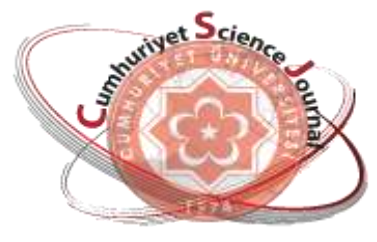

e-ISSN: $2587-246 X$

ISSN: $2587-2680$

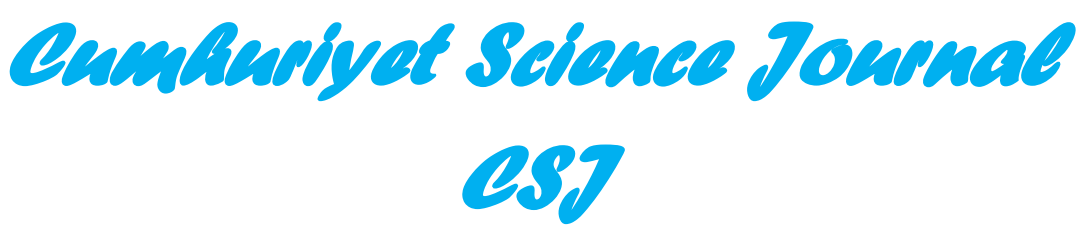

Cumhuriyet Sci. J., Vol.39-1(2018) 16-22

\title{
Iron Interstitial Defects Stability: Under the Uniaxial Stress Effect
}

\author{
Mosab Jaser BANISALMAN*, Takuji ODA \\ Seoul National University, Department of Nuclear Engineering, Gwanak-ro, Gwanak-gu, Seoul 151-742, SOUTH KOREA \\ Received: 30.11.2017; Accepted: 31.01.2018 \\ http://dx.doi.org/10.17776/csj.359753
}

\begin{abstract}
Understanding of defect kinetics under stress fields is important for multiscale modeling of nuclear materials degradation. By means of molecular dynamics (MD) simulation, the formation and migration energies were evaluated for self-interstitial atom (SIA) and SIA clusters (1 3 interstitials) in alpha Fe. Effects of $0 \sim 3 \%$ uniaxial tensile [100] strains were tested for SIAs of $\langle 110\rangle$ and $\langle 111\rangle$ dumbbell configurations. Regarding the stability, the <111> dumbbell configurations becomes more stabilized at larger strains and larger clusters. For the mobility, the diffusion of single SIA defects under tensile stresses were traced. Under the free-strain condition, the diffusivity of the SIA clusters has a gradual transition from three dimensional (3D) to one dimensional (1D) at saturated strain. The 1D transition was observed for large clusters and large strain while the 3D transition was for small clusters and lower strains and presented mainly for the <110> SIA alignment configuration. Under the tensile stress and for small clusters, diffusivity enhancement is bigger at a higher temperature. However, the temperature effect was small for larger clusters. These effects of strain fields can be explained by elastic interaction between defects and applied stress fields.
\end{abstract}

Keywords: Iron, Uniaxial stress, SIA clusters, Kinetics of interstitials, Nuclear structure, Nuclear material. MD

\section{Tek Eksenli Stres Etkisi Altında Demir Çatlak Kusurları Kararlılığı}

Özet: Stres alanlarındaki kusur kinetiğinin anlaşılması, nükleer maddelerin bozulmasının çok boyutlu modellenmesi için önemlidir. Moleküler dinamik (MD) simülasyonu ile, formasyon ve göç enerjisi enerjileri, alfa Fe'de kendiliğinden oluşan atom (SIA) ve SIA kümeleri (1 $\sim 3$ geçiş reklamları) için değerlendirilmiştir. $\% 0 \sim 3$ tek eksenli sürdürülebilir [100] gerilme etkileri $<110>$ SIAs ve $<111>$ halter konfigürasyonları için test edilmiştir. Kararlılık ile ilgili olarak, $<111>$ halter konfigürasyonları daha büyük suşlarda ve daha büyük kümelerde daha kararlı hale gelir. Hareketlilik için, sürdürülebilir gerilmeler altında tek SIA kusurlarının difüzyonu izlenmiş̧ir. Serbest gerilme koşullarında, SIA kümelerinin difüzivitesi, doymuş gerilmede üç boyutlu (3D) ile bir boyutlu (1D) aşamalı bir geçişe sahiptir. 3D geçiş küçük kümeler ve alt gerilmeler için iken ve büyük ölçüde $<110>$ SIA hizalama konfigürasyonu için sunulurken, 1D geçişi büyük kümeler ve büyük gerginlik için gözlenmiştir. Çekme gerilmesi altında ve küçük kümeler için, difüzyon artırımı daha yüksek bir sıcaklıkta daha büyüktür. Bununla birlikte, sıcaklık etkisi daha büyük kümeler için küçüktür. Gerinim alanlarının bu etkileri, kusurlar ve uygulanan stres alanları arasındaki elastik etkileşim ile açıklanabilir.

Anahtar Kelimeler: Demir, Tek eksenli gerilme, SIA kümeleri, Çatlak kinetiği, Nükleer yapı, Nükleer malzeme. MD

\footnotetext{
* Corresponding author. Email address: mosab123@snu.ac.kr

http://dergipark.gov.tr/csj C2016 Faculty of Science, Cumhuriyet University
} 


\section{INTRODUCTION}

In nuclear materials, structure will be subjected to combined time-varying high thermal fluxes and high mechanical stresses. The combined stresses can affect the formation and properties of radiation-induced defects. Also, displacement cascades of these materials. Several of BCC materials which already been used in the nuclear applications such as iron (Fe) and tungsten (W) for were studied under strained conditions as for $\mathrm{W}$ [1] shows a considerable effect on the threshold displacement energy evaluation, while the free strained threshold energy for $\mathrm{W}$ was reported to be $85 \mathrm{eV}[2]$. In alpha iron other studies were conducted for the number of defects generation changes by strain applied [3]. Such work noted a leading change in the predominant defect type, number density, and distribution. This influence has been also observed in alphazirconium[4], copper[5].

Several theoretical studies have been performed to obtain formation and migration energies of defects in alpha Fe by using molecular dynamics (MD) simulations [6-9]. The kinetics of iron defects are needed for multiscale modeling of defect evolution for the reactor applications. There are few studies that investigated the effect of stress on the defect clusters generation in the onset stage of displacement cascade formation and evolution [10] while there are other simulation studies considered the free stress application [3]. Ab-initio calculations were employed to investigate the stability of single self-interstitial atom (SIA) in alpha Fe under external deformation [11].

Only single SIA atom was considered for the archived studies on stress effects on defect formation and defect migration in alpha Fe. From the multiscale point of view, the lack of knowledge on SIA's clusters (containing more than one SIA) has been an issue as it is difficult to acquire the experiential results for such studies.

Therefore, in the present study, by mean of MD simulation, we investigate the formation and migration energies of SIA defects from single
SIA to 3-SIAs clusters under uniaxial strains. The present study includes large strain up to $3 \%$, considering this strain value as a reason for one degradation phenomenon for reactor in-core components driven by the cracking tip, trajectories path defect formation, migration energies and diffusion under strain effect are discussed.

\section{DESCRIPTION OF THE ACTUAL WORK}

All MD simulations were performed by using the LAMMPS code [12]. The interatomic interactions were described with an embeddedatom method (EAM) potential [13], which was developed by Mendelev et al.[14]. The potential was obtained by fitting to both ab initio total energy calculation results and experimentally measured properties. The LAMMPS code is used to simulate defect migration to extract diffusivity and diffusion energies as a function of temperatures. The defect formation energies of different defect configurations calculated as well. The supercell contains $8 \times 8 \times 12(1536) \mathrm{Fe}$ atoms and periodic boundary condition is applied. In order to obtain migration energies, MD simulations are performed at temperatures ranges from $350 \mathrm{~K}$ to $600 \mathrm{~K}$, which are proper to obtain sufficient defect mobility and to avoid clusters dissociation. Under a given temperature the cell is first relaxed using Nose-Hoover style non-Hamiltonian equations of motion to generate positions and velocities sampled from the canonical (NVT) ensemble, the equilibration step allows the lattice to expand to the temperature with a pressure of 0 bar at each simulation cell boundary. Then, the simulation cell is deformed in the x-direction, while the lateral boundaries are controlled using the isothermal-isobaric (NPT) to zero pressure. Stress is applied along [100] direction. SIA dumbbell was introduced by adding two atoms manually into the lattice site after its original atom removed from the deformed structure. The two added atoms were separated by $1 \AA$. The symmetry fixed by zero forcing the $\mathrm{y}$ and $\mathrm{z}$ coordinates of the added SIA's. OVITO code [15] is used to visualize the deformation event as well as to extract and visualize defect diffusion 
trajectories. MD perform constant NVE integration to update position and velocity for atoms each specified time step where $\mathrm{V}$ is volume and $\mathrm{E}$ is energy. By this NVE creates for around 1 nanosecond a system trajectory consistent with the microcanonical ensemble is performed to simulate defect migration.

Diffusivities are determined by

$$
D_{N}=\lim _{t \rightarrow \infty} \frac{R^{2}(t)}{2 \mathrm{ndt}}
$$

$R^{2}(t)$ is the mean-square displacement of the SIAs for time $t, n_{d}$ is the dimensionality of the motion which its eitheir 1D or 3D dimnetions that means the $\mathrm{n}_{\mathrm{d}}$ value might be mainly 1 or 3 , and $\mathrm{t}$ is the simulation time. The migration energies are obtained from temperature dependence of diffusivities as extrapolated from Arrhenius expression:

$$
D_{N}(\mathrm{~T})=D_{o, N}(\mathrm{~T}) \mathrm{e}^{-\mathrm{Em} / \mathrm{kBT}}
$$

where $T$ is the temperature, $k_{B}$ is Boltzmann's constant, $E_{m}$ is the migration energy, and $D_{o, N}(\mathrm{~T})$ is a pre-exponential factor.

\section{RESULTS and DISCUSSION}

Several studies were conducted to understand diffusion mechanisms of SIA clusters in alphairon and other metals [11]. Most of these studies are limited to zero-strain conditions. For 1 3 SIAs, <110> configuration is observed during migration, for temperatures less than $500 \mathrm{~K}$ [10]. 1-SIA dumbbell prefer to have <111> configuration with [100] strain direction under 3 $\%$ strain. For the 2- and 3-SIAs clusters, change of the alignment between $\langle 110\rangle$ and $\langle 111\rangle$ configurations were observed at a specific stage of movement. The results of Table 1 using Arrhenius equation (2) are evaluated to compare the migration energies of small SIA clusters of the present study and selected previous works $[16,17,19]$ (for 0\% strain), although the major focus of the present work is for non-zero strain conditions.
Table 1. Migration energies in $\mathrm{eV}$ for 1 SIA to 3 SIA under $0 \%$, (diffusion pre-exponential factors $D_{0}$, in $10^{-8} \mathrm{~m}^{2} / \mathrm{s}$ ).

\begin{tabular}{lllll}
\hline $\begin{array}{l}\text { Defect } \\
\text { size }\end{array}$ & $\begin{array}{l}\text { Present } \\
\text { Work }\end{array}$ & $\begin{array}{l}\text { Soneda } \\
\text { et al.[13] }\end{array}$ & $\begin{array}{l}\text { Terentyev } \\
\text { et al.[9] }\end{array}$ & $\begin{array}{l}\text { Anento et } \\
\text { al.[14] }\end{array}$ \\
\hline 1 & 0.165 & 0.167 & 0.31 & 0.27 \\
& $(14.6)$ & $(20.9)$ & $(44.2)$ & $(83.1)$ \\
2 & 0.115 & 0.083 & 0.33 & $0.36 \sim 0.44$ \\
& $(23.07)$ & $(7.32)$ & $(243)$ & $(351.6 \sim 4267)$ \\
3 & 0.102 & 0.065 & 0.14 & 0.14 \\
& $(8.5)$ & $(4.82)$ & $(3.35)$ & $(12.1)$ \\
\hline
\end{tabular}

The migration energies of 1 3 SIAs calculated in the present study are comparable with the other studies in Table 1 . The differences would be due to the simulations settings changes of different studeis, as the system size, simulation time, initial SIAs cluster configuration, tempreture sampling and the potential models.

\section{(1) Formation energy}

For self-interstitials, the formation energy decreases with uniaxial increase as in Fig. 1. The reason is when the uniaxial strain is applied an interstitial induces local compressive stresses, which increases the potential energy of the system. Thus a tensile strain reduces this constraint, thereby decreasing the interstitial formation energy while as the defect cluster size increase as given the formation energy increases. The formation energy linearly responds to the strain. It is worthy of note that the formation energy trend changes upon stress can be predicted by elastic interaction between defects and applied stress fields which is also clearly shown in Fig.1.

However, the complexity of this prediction caused by anisotropic strain relaxation which is associated with defect clusters cannot be easily clarified. The quantitative information of defects kinetics as shown in Fig. 1 are necessary for multiscale modeling. At $0 \%$ strain, the 1-SIA takes only $\langle 110\rangle$ configuration during the migration, which leads to $3 \mathrm{D}$ migration due to diffusion mechanism B [19]. This is partly because $\langle 110\rangle$ is the stable configuration at free strain of SIA's in Fig.1. 

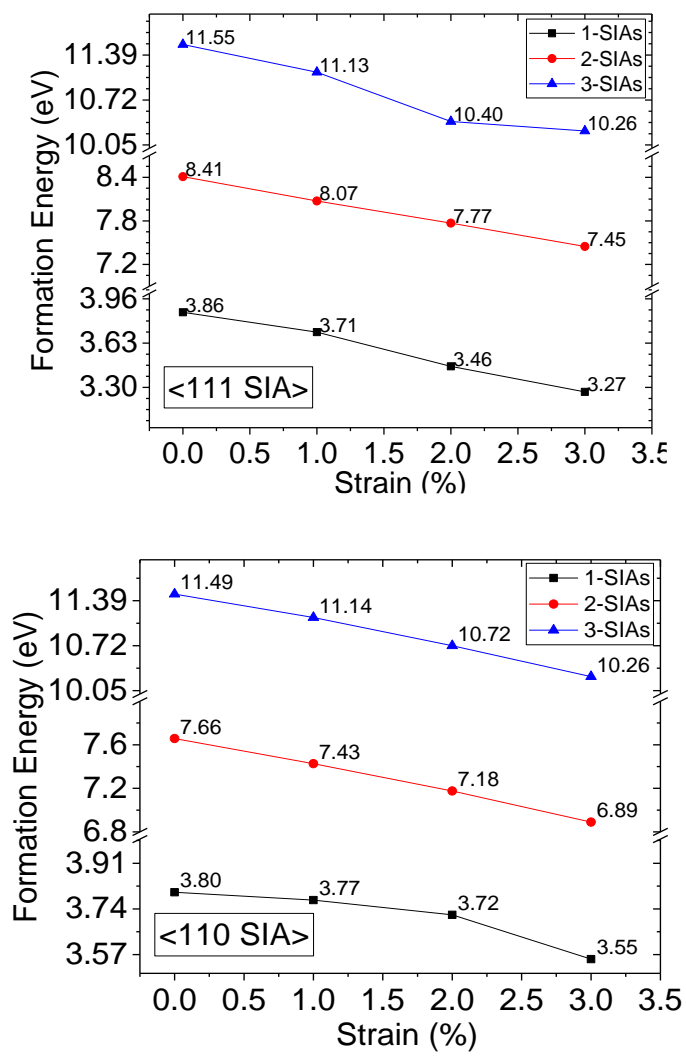

Figure 1. Formation energies of $\langle 111\rangle$ and $\langle 110\rangle$ SIAs defect clusters as a function of strain for cluster containing 1-SIAs, 2-SIAs, 3-SIAs.

Visual inspection at much smaller length scales show that, by increasing the strain, <111> 1-SIA may preferably change from $<110\rangle 1$-SIA. But $<110>1$-SIA appearance quickly changes back to $<111>$.

\section{(2) Diffusion trajectories and diffusivity}

Fig. 2(a-e) plot the diffusion trajectories of 1SIAs and 3-SIAs under 0 3\% strains. The $\mathrm{x}, \mathrm{y}$, $\mathrm{z}$ axes correspond to directions of [100], [010], and [001], respectively. Diffusion trajectories are featured by blue dots forming scattered points or straight-lines along [100] axis. For 1-SIA as shown on Fig.2 a, b diffusion prefers 3D of diffusion trajectories. The trajectories path changed for larger clusters from 3D into 1D as shown in Fig.2 $\mathrm{c}$ and d, of 3-SIA, and 1D diffusion is dominant as shown in (e), featured by line-like diffusion trajectories. Adding tensile strain promotes 1D migration for larger SIAs.
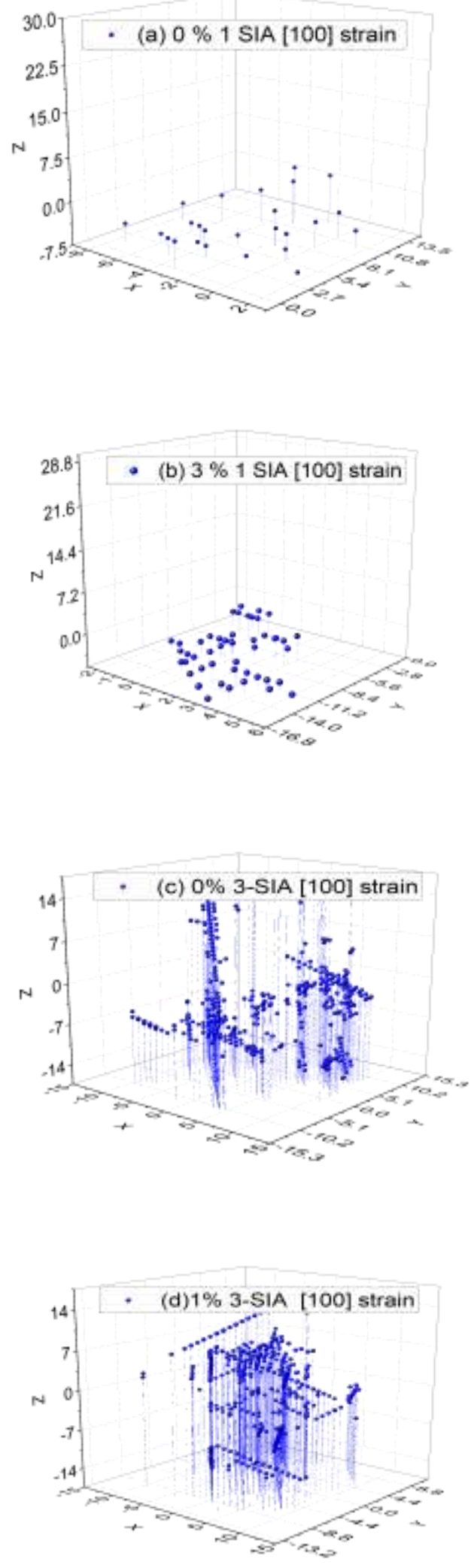


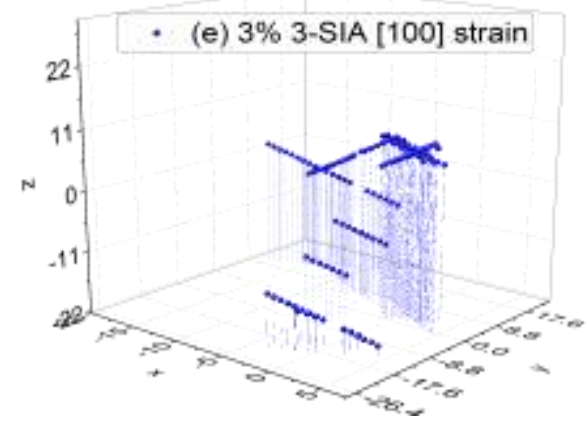

Figure 2. (a-e) average migration path during uniaxial [100] strain application at $490 \mathrm{~K}$. Average migration path means the trajectories of 2-SIA and 3-SIA were averaged of its $\mathrm{x}, \mathrm{y}$ and $\mathrm{z}$ position's configuartion which was extracted by using OVITO code. The average to show only single line trajectory instead of two or three lines that for visulization enhancment purposes.

For the diffusion coefficient evaluation under uniaxial stress Fig. 3 (a, b) show some considerable effects. As the strain increases and the SIA cluster sizes increase, the diffusion coefficient for the 2-SIAs, increase as well. However, we note that the stress effect is dominated over the temperature effects for ranges of a temperature lower than $500 \mathrm{~K}$, which means that if strain increases the diffusion coefficient increase. At $500 \mathrm{~K}$ (corresponding to $\left.1 / \mathrm{k}_{\mathrm{B}} \mathrm{T}=23.21 \mathrm{eV}^{-1}\right) 2 \%$ strain enhances the diffusivity by more than two orders of magnitude compared with the diffusivity at $0 \%$ strain.

The enhancement is higher at higher temperatures. Also For 2-SIA, at higher temperature than $500 \mathrm{~K}$ the temperature effect is dominated over the stress effect that is the reason we see the diffusivities at $2 \%$ strain is higher than the diffusivity at $3 \%$ for temperature above $500 \mathrm{~K}$, the reason for that is due to a specific dumbbell configuration changes occurred during the stress application at higher temperatures. However, the strain effect is dominated over all temperature ranges for 3-SIA which means by stress application increases the diffusivities of 3SIAs increases accordingly.

For defect clusters of 2-SIAs, the strain-induced diffusivity enhancement is relatively less than the enhancements for the clusters of 3-SIAs. A higher strain results in a higher diffusivity, and higher enhancement especially for larger SIAs. The strain has a clear influence on the defect diffusivity, but the effect of strain is quickly saturated. The saturation means that the diffusivities at the highest strain of $3 \%$ are comparable among 2-SIA and 3-SIA cluster sizes. This is due to the significant gliding contributions for larger clusters in diffusion, which will be referred as 3D to $1 \mathrm{D}$ diffusion transition. Under uniaxial strain, linear diffusivity is further promoted but its additional contribution to diffusivity enhancement is limited for larger defect clusters as it will be saturated with $1 \mathrm{D}$ finally.
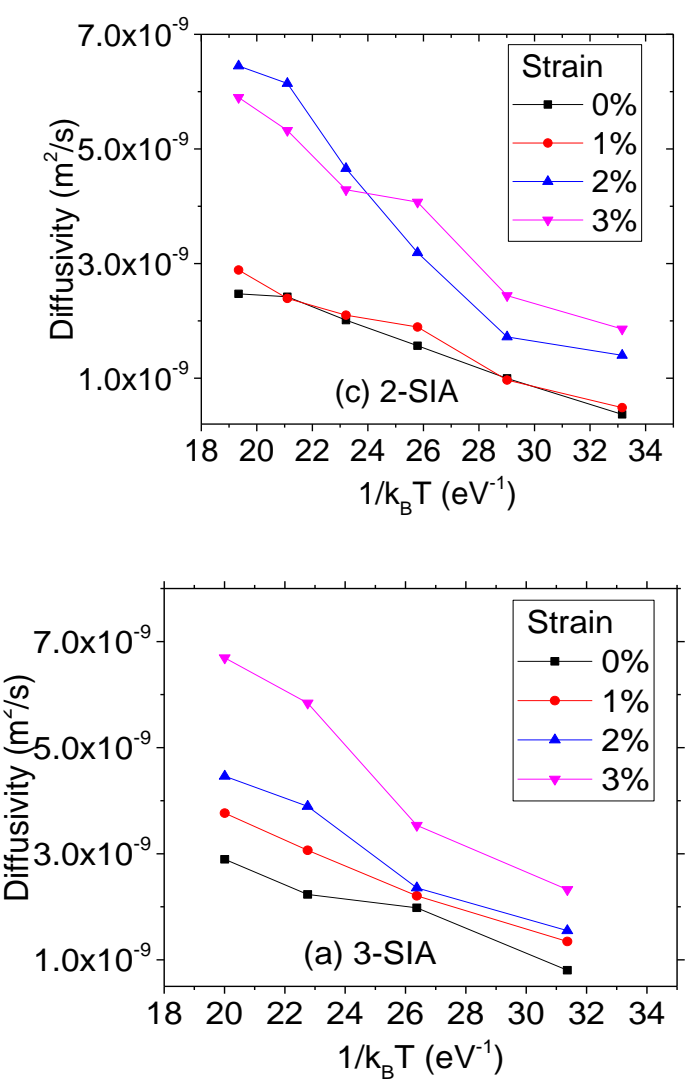

Figure 3. Diffusion coefficients as a function of temperature under different tensile strain along [100] direction for defect clusters containing (a) 2- SIAs, (b) 3SIAs,

\section{(2) Migration energy}

From the diffusion coefficient evaluation at different strain application, the extrapolated migration energies can be calculated. Table 2 summarizes the extracted migration energies and 
diffusivity pre-exponential factors of SIA defect clusters under different strains. Regardless of strain levels, migration energies of defect clusters, in general, become smaller with increasing cluster sizes. Under zero strain, diffusion energies change from $0.165 \mathrm{eV}$ for 1SIA defect to $0.102 \mathrm{eV}$ for 3-SIA defect. Under $3 \%$ tensile strain, the energies change from 0.17 $\mathrm{eV}$ for 1-SIA defect to $0.07 \mathrm{eV}$ for 3-SIA defect.

It is worthy to point out that this study has several limitations. Firstly, although the EAM potential used was qualitatively regenerated the DFT results, it may underestimate the formation energy of $\langle 110\rangle$ and $\langle 111\rangle$, and differences between them, which may impact on the diffusion properties predicted. Secondly, our study is limited to [100] uniaxial strain, since this direction shows the least complexity in direction indices and we need to visualize its effect on diffusivity compared with other direction such as [111] which has been investigated in other studies [10]. Another the SIA's cluster configuration was chosen by taking around 10 different dumbbell configuration and pick up the minimum energy configuration to be inserted manually as our proposed SIA defects. Such as a more advanced method of an advanced algorithm as described by the modified genetic algorithm[20] will result with better SIAs configurations and we will expected different results than reported at this work in term of diffusion coefficients and migration energies. Gathering the diffusion coefficient and migration energy for the main directions [111], [110] and [100] will be useful to present an estimated view for the direction effects to be used with the rate theory applications. While the [110] direction is recommended, the studies on diffusion behaviors under an arbitrary strain direction are still beyond the scope of the present study. The effect of other strains could be very different.
Table 2. Migration energies (eV) and diffusivity prefactors of SIAs defects in parenthesis.

\begin{tabular}{l|llll}
\hline Defects size & $\mathrm{E}_{\mathrm{m}} 0 \%$ & $\mathrm{E}_{\mathrm{m}}{ }^{1 \%}$ & $\mathrm{E}_{\mathrm{m}} 2 \%$ & $\mathrm{E}_{\mathrm{m}} 3 \%$ \\
\hline 1 & 0.165 & 0.164 & 0.181 & 0.17 \\
& $(14.6)$ & $(12)$ & $(5.5)$ & $(13.5)$ \\
2 & 0.115 & 0.138 & 0.101 & 0.08 \\
3 & $(23.07)$ & $(13.6)$ & $(7.4)$ & $(3.3)$ \\
& 0.102 & 0.088 & 0.091 & 0.07 \\
& $(8.5)$ & $(2)$ & $(2)$ & $(3.8)$ \\
\hline
\end{tabular}

\section{CONCLUSION}

We investigate the formation and migration energies of 1 3 SIA defect cluster under uniaxial [100] strain. Regardless of cluster sizes, both $<111\rangle$ and $\langle 110\rangle$ oriented defects have reduced formation energies as applied strain increased. Furthermore, <111> configuration is more sensitive to strain and its defect formation energies are reduced more significantly. There are a divert from <110> SIA to <111> SIA for all defect cluster sizes. For 1-SIA, the migration trajectory is $3 \mathrm{D}$ for all strains, but change from 3D to $1 \mathrm{D}$ gradually with SIA cluster sizes and strains increasing.

$1 \neg 3$ SIAs are more energetically favorable in $\langle 110\rangle$ direction than $\langle 111\rangle$ direction at the free strain.

$\checkmark<111>$ SIA interstitial single or cluster become more stable than $\langle 110\rangle$ for stress conditions.

$\checkmark \quad$ 1-SIA diffusivity increases with increasing strain.

$\checkmark \quad$ Migration energy $\left(\mathrm{E}_{\mathrm{m}}\right)$ decreasing with SIA size's increase.

This work would be important for multiscale modeling application, for example, such result would be used in other large scale simulation methods as in Monte Carlo simulations which treats defect clusters as point-like defects. Diffusivity enhancement and migration energy reduction for larger SIA clusters suggest the role of SIA clusters in defects clustering. Such as combined smaller one into larger ones. 


\section{ACKNOWLEDGEMENT}

This research was supported by National Research Foundation (NRF) of Korea under Nuclear Fusion Basic Research program and by BK 21 plus project in Department of Energy Resource Engineering in Seoul National University.

\section{REFERENCES}

[1]. Wang D., Gao N., Setyawan W., Kurtz R.J., Wang Z.-G., Gao X., He W.-H., Pang L.-L. Effect of Strain Field on Threshold Displacement Energy of Tungsten Studied by Molecular Dynamics Simulation, Chinese Phys. Lett. 33 (2016) 96102.

[2]. Banisalman M.J., Park S., Oda T. Evaluation of the threshold displacement energy in tungsten by molecular dynamics calculations, J. Nucl. Mater. 495 (2017) 277-284.

[3]. Beeler B., Asta M., Hosemann P., Grønbechjensen N. Effects of applied strain on radiation damage generation in body- centered cubic iron, J. Nucl. Mater. 459 (2015) 159-165.

[4]. Lewis T.A., Gao F., Bacon D.J.. Flewitt P.E.J. The influence of strain on defect generation by displacement cascades in alpha-Fe, Nucl. Instruments Methods Phys. Res. Sect. B Beam Interact. with Mater. Atoms. 180 (2001) 187193

[5]. Miyashiro S., Fujita S., Okita T. MD simulations to evaluate the influence of applied normal stress or deformation on defect production rate and size distribution of clusters in cascade process for pure $\mathrm{Cu}, \mathrm{J}$. Nucl. Mater. 415 (2011) 1-4.

[6]. Fu C., Willaime F. Stability and Mobility of Mono- and Di-Interstitials in -Fe, (2004) 1-4.

[7]. Osetsky Y.N., Serra A., Singh B.N., Golubov S.I. Structure and properties of clusters of selfinterstitial atoms in fcc copper and bcc iron, 8610 (2017).

[8]. Osetsky Y.N. Atomistic study of Diffusional Mass Trasnport in Metals, Defect and Diffsuion Forum (2001) 71-92.

[9]. Wirth B.D., Odette G.R., Maroudas D., Lucas G.E. Energetics of formation and migration of self-interstitials and self-interstitial clusters in $\alpha$-iron, J. Nucl. Mater. 244 (1997) 185-194

[10]. Kang C., Wang Q., Shao L. Kinetics of interstitial defects in a -Fe: The effect from uniaxial stress, J. Nucl. Mater. 485 (2017) 159-168.

[11]. Chen Z., Kioussis N., Ghoniem N., Seif D. Strain-field effects on the formation and migration energies of self interstitials in a $-\mathrm{Fe}$ from first principles, (2010) 1-10.

[12]. Plimpton S. Fast Parallel Algorithms for Short-Range Molecular Dynamics, J. Comput. Phys. 117 (1995) 1-19.

[13]. Daw M.S., Baskes M.I. Embedded-atom method: Derivation and application to impurities, surfaces, and other defects in metals, Phys. Rev. B. 29 (1984) 6443-6453.

[14]. Mendelev M.I., Han S., Srolovitz D.J., Ackland G.J., Sun D.Y., Asta M. Development of new interatomic potentials appropriate for crystalline and liquid iron, Philos. Mag. 83 (2003) 3977-3994.

[15]. Alexander K.C., Schuh C.A. Visualization and analysis of atomistic simulation data with OVITO - the Open Visualization Tool, Model. Simul. INMATERIALS Sci. Eng. 18 (2010) 7.

[16]. Terentyev D.A., Malerba L., Hou M. Dimensionality of interstitial cluster motion in bcc-Fe, Phys. Rev. B - Condens. Matter Mater. Phys. 75 (2007) 1-13.

[17]. Willaime F., Fu C.C., Marinica M.C., Torre J.D. Stability and mobility of self-interstitials and small interstitial clusters in a -iron: ab initio and empirical potential calculations, 228 (2005) 92-99.

[18]. Anento N., Serra A., Osetsky Y.N. Atomistic study of multimechanism diffusion by selfinterstitial defects in $\alpha$-Fe, Model. Simul. Mater. Sci. Eng. 18 (2010) 25008.

[19]. JOHNSON R.A. Interstitials and Vacancies in a-Iron, Phys. Rev. 134 (1964) A1329 A1336.

[20]. Kaczmarowski A., Yang S., Szlufarska I., Morgan D. Genetic algorithm optimization of defect clusters in crystalline materials, Comput. Mater. Sci. 98 (2015) 234-244. 